Fanum

Sociológico

\section{Forum Sociológico}

Série II

$19 \mid 2009$

As Forças Armadas numa sociedade em mudança

\title{
Os diplomados do ensino superior perante $o$ mercado de trabalho: velhas teses catastrofistas, aquisições recentes
}

Miguel Chaves, César Morais e João Sedas Nunes

\section{(2) OpenEdition \\ Journals}

Edição electrónica

URL: https://journals.openedition.org/sociologico/312

DOI: 10.4000/sociologico.312

ISSN: 2182-7427

Editora

CICS.NOVA - Centro Interdisciplinar de Ciências Sociais da Universidade Nova de Lisboa

Edição impressa

Data de publição: 1 junho 2009

Paginação: 83-98

ISSN: 0872-8380

Refêrencia eletrónica

Miguel Chaves, César Morais e João Sedas Nunes, «Os diplomados do ensino superior perante o mercado de trabalho: velhas teses catastrofistas, aquisições recentes», Forum Sociológico [Online], 19 | 2009, posto online no dia 20 julho 2012, consultado o 29 março 2022. URL: http://

journals.openedition.org/sociologico/312 ; DOl: https://doi.org/10.4000/sociologico.312

Este documento foi criado de forma automática no dia 29 março 2022.

(C) CICS.NOVA 


\title{
Os diplomados do ensino superior perante o mercado de trabalho: velhas teses catastrofistas, aquisições recentes
}

\author{
Miguel Chaves, César Morais e João Sedas Nunes
}

\section{Introdução}

1 Os discursos catastrofistas acerca da situação que os diplomados do ensino superior enfrentam no mercado de trabalho têm, pelo menos desde há duas décadas, proliferado em Portugal. Com destaque para as esferas mediática e política, mas também, por vezes, no quadro das ciências sociais, assume-se com frequência que o desemprego, a aceitação de posições profissionais abaixo do nível de escolaridade alcançado ou que se encontram desajustadas face à área de formação são, hoje em dia, realidades de larga escala experienciadas pelos diplomados do ensino superior, insinuando-se, não poucas vezes, que constituem regras às quais se furta apenas uma minoria afortunada de cursos e graduados.

2 Nesses discursos a tese do "cenário catastrófico" reveste a forma de evidência indiscutível, a ponto de não merecer contestação, exame crítico, ou sequer confronto com os dados disponíveis.

O mesmo poderá afirmar-se de uma outra tese que se lhe encontra estreitamente associada - a do "desalento generalizado". Com efeito, aceita-se igualmente de forma pacífica que, ao confrontarem-se com a experiência do desemprego e da precariedade, com o defraudar das expectativas de mobilidade social e com a impossibilidade de obterem recompensas remuneratórias e estatutárias ajustadas ao (elevado) patamar escolar alcançado, os diplomados deixam-se tomar, invariavelmente, por sentimentos de frustração tanto face ao seu destino profissional quanto ao patamar e/ou à área dos títulos académicos em que se formaram. 
4 Sujeitar estas duas teses ao escrutínio da empiria - aproveitando para conferir a esta última uma visibilidade de que geralmente não beneficia - constitui o motivo central deste artigo. Veremos que tais teses resistem com dificuldade ao confronto com a evidência empírica disponível. No que se refere à "tese do desalento generalizado", iremos um pouco mais longe. Assumindo um registo mais interpretativo, e densificando a sua desmontagem, procuraremos avançar algumas notas explicativas sobre as razões que fazem que esta não se confirme, pelo menos considerando os dados disponíveis.

5 Os dados que aqui iremos convocar de forma sistemática resultam de diversas pesquisas que versaram a inserção profissional de graduados portugueses. Para as seleccionar, assumimos dois critérios idênticos aos adoptados por Mariana G. Alves (2010) em artigo em que procurava reflectir sobre as metodologias utilizadas nessas análises: a) os estudos não poderiam ser anteriores à presente década e b) deveriam abranger a totalidade dos graduados de uma dada entidade (universidade, escola politécnica ou faculdade), não se circunscrevendo a um determinado curso ou conjunto de cursos. Não é certo que se tenham abrangido todos os estudos realizados em Portugal que respeitam os dois critérios. Foram incluídos os mais divulgados e publicitados, e ainda outros sinalizados pelas instituições académicas que contactámos. Verificámos mais tarde que esses estudos correspondem aos retidos numa obra que procurou reunir os estudos mais significativos realizados a nível nacional sobre a inserção profissional de diplomados (Marques e Alves, 2010), embora lhes tenhamos associado ainda alguns outros.

6 Os critérios de selecção indicados colocaram-nos assim perante o apuramento do ODES (2002), o único centrado sobre a globalidade dos graduados (mais exactamente licenciados) do ensino superior português, facultando por isso mesmo, apesar da sua maior desactualização, uma ideia de conjunto que não é oferecida por nenhum dos outros. Numa escala mais reduzida, mobilizou-se um estudo centrado no Algarve (Geraldes e Santos, 2004), que tem a particularidade de agregar os dados sobre a Universidade do Algarve com os de outras instituições do ensino superior situadas nessa região ${ }^{1}$, assim como os estudos desenvolvidos na Universidade de Aveiro (Martins, Arroteia e Gonçalves, 2002), Universidade de Évora (Vieira, Raposo e Santos, 2008), Universidade de Lisboa (Alves, 2005), Universidade do Minho (Gonçalves, 2001) e Universidade do Porto (Gonçalves, Menezes e Martins, 2009). No que se refere ao ensino politécnico recorreu-se a dois trabalhos que, sobre esta fileira de ensino, têm vindo a ser publicitados, de forma mais sistemática, em contexto científico: um produzido acerca dos diplomados do Instituto Politécnico de Beja (Saúde, 2005) e outro sobre a Escola Superior de Ciências Empresariais, sediada em Setúbal (Almeida, Vaz, Marques e Dominguinhos, 2007). Por fim, e no que concerne a escolas/faculdades encaradas singularmente, utilizamos os dados apurados acerca da Faculdade de Ciências Sociais e Humanas da Universidade Nova de Lisboa (Chaves e Morais, 2008) e os recolhidos para o Instituto Superior Técnico da Universidade Técnica de Lisboa (Mendes, Patrício e Lucas, 2006). Todos os estudos se debruçam sobre universos de licenciados, não obstante alguns deles poderem também incluir mestres e doutores que não são porém identificados e muito menos destacados enquanto segmento.

7 Procuraremos complementar este repertório multi-institucional de dados com outros, mais recentes, contidos no Inquérito ao Emprego do INE, relativos ao 3.. trimestre de 2010. Embora esse apuramento não possua informação sobre diversas dimensões contempladas pelo menos parcialmente nos estudos que seleccionámos, tem a virtude 
de trabalhar sobre uma amostra representativa da população portuguesa, nomeadamente a que concluiu o ensino superior. Além disso, permite desenvolver, facultando informações actualizadas, uma leitura comparativa entre a população graduada do ensino superior e a que não concluiu esse grau de ensino ${ }^{2}$.

8 Antes de prosseguir, duas ressalvas fundamentais: não obstante o texto proponha, em alguns momentos, uma leitura retrospectiva e evolutiva da situação dos diplomados perante o mercado de trabalho, o propósito nodal é observar com rigor a situação presente, cotejando, nos casos em que tal se afigure possível, a situação dos graduados com a da população que não dispõe de títulos escolares de grandeza análoga. Os limites de extensão impõem que as análises diacrónicas sejam reservadas para outro artigo, complementar a este.

Segunda nota: embora os estudos mobilizados versem uma temática comum, os procedimentos metodológicos que utilizam são muito díspares, desautorizando, por esse motivo, qualquer comparação de resultados. Tornou-se possível recorrer a todos eles, de forma simultânea e cumulativa, na medida em que, não obstante as profundas dissemelhanças, os dados neles ventilados apontavam, no que concerne às temáticas em apreço, direcções e sentidos interpretativos comuns.

\section{Teses catastrofistas, contrateses sociológicas: um breve estado da arte}

10 É hoje em dia comum enunciar-se que o cenário observável durante as três primeiras décadas do pós-guerra, no qual a obtenção de um diploma superior permitiria aos seus detentores ingressar rapidamente no mercado de trabalho e garantir recompensas económicas, estatutárias e simbólicas incontestáveis, em grande medida vedadas àqueles que não o possuiriam, se tem vindo a dissipar paulatinamente ao longo do tempo. Essa diluição não seria mais do que o resultado lógico de fenómenos bem realçados de "massificação" no acesso ao ensino superior, de "inflacionamento" dos títulos obtidos e da sua concomitante "perda de raridade" (Bourdieu, 1979: 148; Bourdieu e Champagne, 1993: 599-602; Nicole-Drancourt e Roulleau-Berger, 2001; Galland, 1991; Petitat, 1994: 259), acompanhados da impossibilidade de se produzirem oportunidades de trabalho a um ritmo similar àquele em que decorre a produção de graduados (Canário, 2008: 78).

11 Há muito destacadas no âmbito da análise sociológica, e em certa medida testadas, estas teses não nos merecem nem absoluta reserva nem apoio incondicional ${ }^{3}$. Se Petitat (1994: 259) respeitavelmente afirma "Quem diz massificação diz desvalorização, tão seguramente quanto se se passasse de uma praia particular para uma praia pública", já Maurin, em contrapartida, se refere à tese da desvalorização dos diplomas, apelidandoa de "mito" (2007: 160-2). Quanto a este aspecto, a nossa posição é tão-só a de que se trata de conjectura intelectualmente estimável mas a que não podemos atribuir força de lei social muito menos comprovada. Mais, casos estudados como os de França, Reino Unido e Países Escandinavos (ibidem) sugerem que tal tese é infundada (Nunes, 2011: 592).

12 Muito menos hesitação nos suscita um conjunto de outras ideias que se têm vindo a impor também há alguns anos em Portugal, e que aqui nos dedicaremos a rebater. Em concreto, elas gravitam em torno da tese de que, presentemente, muitos diplomados 
(porventura a sua maioria) não conseguiriam inserir-se no mercado de trabalho, expondo-se a desemprego duradouro. Para o evitar, teriam forçosamente, e de forma generalizada, de "lançar mãos" a actividades incompatíveis com o grau de escolaridade obtido e com as áreas em que se formaram. A situação seria, portanto, e já hoje, catastrófica. A vulgata mediática tem propagado essa representação: o licenciado em Direito "que serve bicas", o diplomado em História que conduz um táxi, a graduada em Línguas e Literaturas que permanece há anos na caixa de um supermercado são apresentados não como casos esporádicos muito menos residuais, mas como a regra a que só se furta uma minoria privilegiada. Na sequela destas pré-noções a passagem pelo ensino superior é concebida muitas vezes como uma vacuidade, como algo sem sentido, sobretudo por aqueles que a avaliam tendo em mente preocupações exclusivamente instrumentais.

As objecções que colocamos a estas teses, e a exigência de que estas passem a ser tratadas com especial prudência, resultam da observação transversal e aturada dos dados empíricos sobre a inserção profissional dos graduados portugueses. Embora a colecta de dados sobre as instituições académicas dê a conhecer uma significativa pluralidade inter-institucional no que concerne as modalidades de inserção profissional dos graduados portugueses, a regra não parece vingar, nem mesmo nas áreas de estudos que, na visão mais alarmista, lhe estariam mais expostas: as artes e as humanidades, as ciências sociais e humanas e, eventualmente, o Direito. E parece também não se verificar se colocarmos a questão num plano internacional. Ao observarmos os dados de projectos de investigação realizados por redes internacionais como é o caso do "Higher Education and Graduate Employment in Europe" (CHEERS), levado a cabo entre 1998 e 2000 (Shomburg e Teichler, 2006; Teichler (ed.), 2007), ou do "Research into Employment and Professional Flexibility" (REFLEX), realizado em 2005 (Allen e Velden, 2007), chegamos forçosamente a essa conclusão, conclusão que é também a de Carlos M. Gonçalves (2010), embora, tal como ele, frisemos que o posicionamento e as modalidades de inserção dos diplomados no mercado de trabalho variam conforme o país e a área científica de formação.

Os reparos que aqui fazemos não são portanto inéditos. Vários sociólogos portugueses que têm directamente trabalhado acerca da inserção laboral deste tipo de populações, como é o caso de Miguel Chaves (2010), Natália Alves (2008) e Mariana G. Alves (2007), têm assinalado o desfasamento entre o propalado cenário catastrófico e os resultados com que se deparam nos estudos por si conduzidos. Também o economista Pedro Portugal, recorrendo aos dados do INE referentes a 2003, constatou que em diversos domínios da relação com o mercado de trabalho - a probabilidade dos indivíduos se depararem com uma situação de desemprego; a qualidade dos vínculos laborais e o rendimento - a situação dos diplomados é bastante mais favorável do que a dos indivíduos que não foram além do 3. ciclo do ensino básico, concluindo assim que os primeiros tendem "a atrair uma atenção desproporcionada da comunicação social" (Portugal, 2004: 73).

15 Talvez por se ampararem em conjuntos de dados contextualmente restritos, e por não serem suficientemente enfatizadas, estas conclusões têm tido pouca ressonância nas ciências sociais portuguesas e um eco ainda mais débil fora do campo científico. Propomo-nos, nessa medida, ir mais longe. Recorreremos a um volume considerável de informação empírica, infelizmente esparsa, e reuni-la-emos para dela extrairmos dividendos analíticos acerca da situação dos diplomados na actualidade. Conduziremos 
a observação através de cinco itinerários que consideramos centrais: a situação perante o trabalho; o grau de ajustamento entre o nivel/género de formação e a actividade profissional; os niveis de rendimento; a situação contratual e, por fim, a avaliação que os diplomados produzem da sua situação profissional.

\section{Situação perante o trabalho}

16 Os dados disponíveis estão, neste capítulo, longe de corroborar a tese do desemprego massivo. Se contemplarmos, em primeiro lugar, o estudo ODES (2002), o único que, como apontámos, foi realizado à escala nacional, verificamos que, cinco anos volvidos sobre a obtenção do grau, a taxa de desemprego não ia além de 1,9\%, encontrando-se nesse momento empregados $95,7 \%$ do total de indivíduos graduados em 1994/95. Mesmo na área que registava a maior taxa de desemprego - Artes e Humanidades -, o referido índice não ultrapassava os $4,2 \%{ }^{4}$, devendo acrescentar-se que, numa avaliação subjectiva, $80,4 \%$ dos diplomados, entre os quais se incluem aqueles que já desempenhavam papéis profissionais antes de concluírem o curso ou até antes de o haverem iniciado, afirmavam que o facto de terem concluído o ensino superior lhes havia ampliado o leque de oportunidades profissionais.

O estudo do ODES utilizou, para medição do desemprego, os critérios do INE (no fundo, os oficiais) que, como é sabido, são particularmente restritivos na classificação de "desempregado"s. A esta opção se deve, não temos dúvidas, a obtenção de resultados excepcionalmente animadores. Contudo, nem só nesse estudo o propalado cenário do desemprego massivo perde terreno.

Se observarmos os dados produzidos pelas próprias instituições académicas, começando pelos apuramentos obtidos em universidades, notamos que a percentagem de desempregados à data em que foram conduzidas as inquirições não vai além de 7,4\% na Universidade de Aveiro (Martins, Arroteia e Gonçalves, 2002: 55) e de 6,9\% na Universidade do Minho (Gonçalves, 2001: 19), tange os dois dígitos na Universidade do Porto (9,9\%) (Gonçalves, Menezes e Martins, 2009: 9), ultrapassando-os nos três outros casos para os quais dispomos de registos $-12 \%$ no conjunto das instituições académicas algarvias (Geraldes e Santos, 2004: 93), 12,7\% na Universidade de Évora (Vieira, Raposo e Santos, 2008: 6) e 15,5\% na Universidade de Lisboa (Alves, 2005: 38).

Para este intervalo de desemprego convergem os dados colhidos para os institutos politécnicos - a percentagem de desempregados atinge os $15,2 \%$ no Instituto Politécnico de Beja (Saúde, 2005: 32), e não vai além dos 5\% na ESCE (Almeida, Vaz, Marques e Dominguinhos, 2007: 25).

Nos estudos centrados apenas em faculdades ou em institutos, verificamos, por sua vez, que a percentagem de desempregados é de 6,2\% no Instituto Superior Técnico (Mendes, Patrício e Lucas, 2006: 43), não indo além de 4,8\%, cerca de cinco anos após a obtenção do grau, na Faculdade de Ciências Sociais e Humanas da UNL (Chaves e Morais, 2008: 13).

21 É certo que os valores do desemprego com que deparamos nestes estudos parcelares são, em qualquer dos casos, superiores aos do último período que consta do inquérito nacional ODES ( 5 anos após a conclusão da licenciatura). Tal não surpreende. Sem pôr em causa a capacidade explicativa atribuível a factores como o agravamento da conjuntura económica e o recuo do Estado enquanto entidade empregadora que 
ganharam expressão nos últimos anos (o estudo do ODES incide sobre uma coorte mais remota do que os demais), as diferenças registadas dever-se-ão sobretudo às disparidades de indicadores utilizados (menos restritivos do que os do INE na atribuição da categoria de "desempregado") e ao facto de todos eles incidirem em universos de graduados que, na totalidade, ou na sua grande maioria, concluíram os cursos há menos de 5 anos $^{6}$.

Ora, conferir atenção à extensão do período que medeia entre a obtenção do diploma e o momento de inserção no mercado de trabalho afigura-se muito relevante para que destes dados se possa produzir uma leitura rigorosa e concludente. Como já havia assinalado M. G. Alves $(2007,2009)$, os estudos que recaem nesta problemática mostram que o desemprego dos licenciados a) tende a ser extremamente elevado nos primeiros trinta dias após a conclusão do curso; b) reduz-se substancialmente a partir do sexto mês; e c) atinge proporções muito reduzidas no final de cinco anos. Essa é de resto a tendência verificada no levantamento do ODES (2002: 24), onde a taxa de desemprego regista quebras constantes ao longo de cinco anos - se um mês após a licenciatura era ainda de $39 \%$, cai abruptamente para $4,7 \%$ ao $18 .^{\circ}$ mês e para $1,9 \%$ no final do primeiro quinquénio -, assim como no estudo realizado na FCSH da UNL (Chaves e Morais, 2008: 13), o único que seguiu critérios e indicadores similares aos do ODES, procurando acompanhar a situação dos diplomados no mercado de trabalho até 60 meses após a conclusão da licenciatura - a taxa de desemprego situava-se em $26 \%$ no final do primeiro mês, em $8,8 \%$ e 9,2\% atingidos respectivamente os 18 e os 36 meses e em 4,8\% alcançado o limite de 5 anos.

Tendência similar de redução progressiva mas substancial da incidência do desemprego parece evidenciar-se nos dados do INE referentes ao Inquérito ao Emprego do terceiro trimestre de 2010 (o mais recente no momento em que foi redigido o presente texto), ao observar-se o volume de desempregados em cada uma das categorias etárias. Se a percentagem de graduados desempregados se eleva a $17,2 \%$ no escalão dos 15 aos 24 anos (escalão composto na sua esmagadora maioria por sujeitos que completaram a sua formação superior há 2-3 anos), reduz-se para 9,5\%, no escalão etário seguinte (25-34 anos), caindo ainda mais no escalão posterior (35-44 anos, em que a grande maioria dos indivíduos certamente já completou a sua licenciatura há mais de 5 anos), para a casa dos $4,6 \%$.

Procurando agora comparar as percentagens de desempregados registadas nos diferentes segmentos etários juvenis para diversos níveis de instrução (INE, 2010), verificamos que para os escalões etários 25-34 anos e 35-44 anos as proporções de desempregados com nível de instrução superior são menores do que as médias obtidas para o total da população nesses mesmos intervalos etários (respectivamente $11,8 \% \mathrm{e}$ $8,7 \%$ ), e são também mais baixas do que as que se podem encontrar em qualquer outro nível de instrução considerado singularmente.

Não finalizaremos este ponto sem chamar a atenção para um conjunto de valores que, embora raramente referidos, são de considerável importância. Trata-se da colecção relativa ao peso dos "inactivos". Nos intervalos etários 25-34 anos e 35-44 anos os inactivos representam respectivamente $5,4 \%$ e $2,6 \%$ dos diplomados, bem abaixo da expressão que têm $(10,0 \%$ e 9,3\%) na população total com as mesmas idades.

26 Estes baixos valores de inactividade traduzirão, antes de mais, a forte relação dos diplomados portugueses com o mercado de trabalho, tudo indica mais intensa do que a verificada na maioria dos países europeus. Com efeito, segundo os dados do EUROSTAT 
(Dornelas (org.), 2011: 36) a "taxa de emprego" dos diplomados portugueses é superior à registada para a média dos diplomados da UE27. Em segundo lugar, eles indicam-nos que o efeito do prolongamento dos estudos na redução da taxa de desemprego dos diplomados não é afinal de monta, ao contrário do que por vezes se conjectura. Finalmente, a baixa taxa de inactividade dos diplomados é um dado ainda a equacionar quando se comparam as taxas de desemprego dessa população com a dos segmentos da população que dispõem de níveis de instrução inferiores. Uma vez que essa taxa é calculada apenas em relação à população activa, isso significa que, ceteris paribus, a menor percentagem de inactivos provoca uma elevação da taxa de desemprego, enfraquecendo assim por mero efeito estatístico a posição relativa dos diplomados no cômputo geral da população. Dir-se-ia, em suma, que mesmo nas categorias etárias mais novas, e apesar de contarem com níveis de inactividade menores, os diplomados continuam a registar taxas de desemprego inferiores à população geral.

\section{(Des)ajustamento entre o nível/género de formação e a actividade profissional}

27 A segunda ideia muito presente nas acepções de cariz catastrofista prende-se ao conteúdo das funções e actividades profissionais realizadas pelos diplomados. Alega-se que estas são, regra geral, muito desadequadas face ao nível escolar alcançado e ao tipo de formação obtido: "verticalmente e horizontalmente desajustadas", para utilizarmos os termos avançados por Storen e Arnesen (2007: 224-25) na apresentação dos dados do projecto REFLEX 7 . Se tal conjectura fosse empiricamente corroborada, poderia inclusive supor-se que os níveis de desemprego dos diplomados afinal não ascenderiam a valores consideravelmente mais elevados pela simples razão de que esses indivíduos se encontrariam a experienciar "em massa" uma situação de desajustamento entre o nível e a área de formação alcançados e a actividade profissional. Tudo se passaria, no fundo, como se assistíssemos ao reeditar da "catástrofe", agora sob outras roupagens - já não a do desemprego, mas a da desadequação.

No entanto, também este argumento não colhe nos dados disponíveis, sobretudo no que concerne a putativa dissociação entre as actividades profissionais e os níveis de formação, isto é, ao "desajustamento vertical", desajustamento que traduz, no fundo, uma situação de sobrequalificação.

No inquérito ODES (2002: 38), verificamos que, ao fim de 5 anos, é superior a $70 \%$ o número de diplomados que caem nas categorias profissionais dos "Quadros Superiores da Administração Pública; Dirigentes e Quadros Superiores de Empresas" e dos "Especialistas das Profissões Intelectuais e Científicas", categorias que, na esmagadora maioria dos casos, encerram formações superiores. Os "Técnicos e Profissionais de Nível Intermédio" - a categoria menos polarizada por recursos escolares - representa $21,2 \%$ do total, atendo-se a $7,2 \%$ o número de indivíduos afectos a categorias profissionais que, regra geral, não exigem formações superiores: o "Pessoal Administrativo e Similares", o "Pessoal dos Serviços e Vendedores" e os "Operários".

Este quadro de tendencial homologia entre o nível de formação e a actividade profissional capta-se ainda em estudos mais actualizados (embora mais parcelares) que decalcaram as categorias profissionais do ODES. Se para todos eles replicarmos o raciocínio anterior, diríamos que se situa quase sempre na cifra dos $70 \%$ (isto é, em 
mais de dois terços) o número de indivíduos que denotam ajustamento entre nível académico e categoria profissional. Na Universidade de Lisboa (Alves, 2005: 46), por exemplo, a porção dos "pertencentes" às categorias dos "Quadros Superiores da Administração Pública; Dirigentes e Quadros Superiores de Empresas" e dos "Especialistas das Profissões Intelectuais e Científicas" ultrapassa expressivamente essa fasquia; fasquia, por seu turno, quase alcançada na Universidade do Porto $(69,8 \%)$ (Gonçalves, Menezes e Martins, 2009: 10). Por contraste (não muito significativo), na FCSH-UNL (Chaves e Morais, 2008: 16) a percentagem de indivíduos que, ao fim de aproximadamente 5 anos, haviam transitado para aquelas categorias profissionais é mais reduzida, situando-se na casa dos $62,3 \%$, embora devamos ter presente que nos encontramos aqui, em exclusivo, perante formações em ciências sociais e humanas, reconhecidamente confrontadas com horizontes de inserção mais periclitantes.

Na Universidade de Aveiro (Martins, Arroteia e Gonçalves, 2002: 85) as categorias profissionais utilizadas no apuramento são distintas das convocadas nos estudos antes referidos ${ }^{8}$. No entanto, se descontarmos todas as que não implicam necessariamente, para as integrar, posse de diplomas superiores - os "Professores do 1.. Ciclo e os educadores de infância" (7,5\%), os "Profissionais Técnicos intermédios" (9,2\%), os "Empregados administrativos" (3\%) e os indivíduos inscritos na categoria "Outros" $(8,3 \%)$-, volta de novo a aproximar-se dos $70 \%$ o total de ingressados em categorias profissionais aparentemente ajustadas ao nível de instrução superior.

o desajustamento horizontal - isto é, o grau de desadequação entre o conteúdo da formação e as actividades laborais realizadas - é, por sua vez, particularmente difícil de ponderar. Mesmo não se trazendo à colação uma crítica do pressuposto "adequacionista" que subjaz a este género de mensuração (discussão que extravasa os propósitos deste artigo), é forçoso reconhecer que os problemas metodológicos que a própria medição coloca são extremamente difíceis de solucionar. De facto, que critérios e indicadores adoptar num sem-número de formações onde a (in)compatibilidade entre a área de formação e o "destino profissional" está longe de poder ser definida de forma unívoca e objectiva? Perante a ausência de uma resposta satisfatória, a opção aparentemente unânime nos estudos realizados tem sido a de propor aos próprios diplomados que avaliem o grau de ajustamento da sua formação à situação profissional (emprego) em que enfileiraram.

33 Nesta solução subjectivista, embora a percepção do grau de adequação varie de curso para curso, a clara maioria dos jovens diplomados portugueses afirma que a sua actividade profissional corresponde à sua área de formação. No inquérito ODES (2002: 125), $89,9 \%$ dos indivíduos consideravam existir uma adequação entre a sua formação e o emprego, juízo de adequação que conhecia o seu valor máximo na área da Saúde, atingindo aí os $99,2 \%$, e o mais baixo nas ciências sociais e comportamentais, onde não ultrapassava os 73,6\%. Na Universidade de Lisboa (Alves, 2005: 109), 72\% dos inquiridos estimavam que a sua ocupação profissional se "relacionava com a área do curso", e 14\% que se situava em "área próxima"; na Universidade do Porto (Gonçalves, Menezes e Martins, 2009: 19), 59,9\% consideravam que "as funções desempenhadas no emprego actual só podiam ser executadas por alguém com a mesma licenciatura", e $21,2 \%$ por alguém com um título superior, embora este pudesse diferir do seu. Os dados referentes à UP contêm ainda uma curiosa informação suplementar - ao avaliarem numa escala de 5 pontos a adequação entre o "emprego actual" e a "formação académica", a média apurada rondou o grau $4(3,92)^{9}$. Na Universidade do Minho (Gonçalves, 2001: 43), 65\% 
responderam afirmativamente quando instados a referirem se a sua actividade profissional se relacionava com o seu curso, enquanto outros $16 \%$ consideraram que essa articulação se verificava, ao menos em parte. Por seu lado, o estudo que recobre várias instituições de ensino superior algarvias (Geraldes e Santos, 2004: 82) alberga os seguintes dados: a área de actividade é julgada "directamente relacionada" com o curso por $58,4 \%$, e "próxima" por $26,1 \%$; ao passo que, junto dos graduados do Politécnico de Beja (Saúde, 2005: 45), 70\% consideraram a formação "adequada" e 12,9\% "muito adequada" ao seu curso. Por fim, na Faculdade de Ciências Sociais e Humanas da Universidade Nova de Lisboa (Chaves e Morais, 2008), 66\% declararam ter (ou já ter tido) uma actividade ajustada ao seu curso, ascendendo a $79,2 \%$ a parcela dos que consideram que essa actividade corresponde (ou já correspondeu), ao menos em parte, à posse de formação superior.

Em suma, é, em qualquer dos casos, francamente maioritário o número daqueles que consideram existir uma adequação/correspondência entre curso e área de actividade profissional, e mais amplo ainda o daqueles que entendem existir uma convergência entre a actividade profissional e o patamar escolar alcançado.

\section{Níveis de rendimento}

É sem dúvida no domínio da comparação entre indivíduos com diferentes níveis de instrução que as teses catastrofistas têm de ser usadas com mais cautela e parcimónia. Como notaremos adiante, recorrendo aos dados do INE, são flagrantes as disparidades entre as remunerações dos diplomados do ensino superior (mesmo nas faixas etárias recém-ingressadas no mercado de trabalho) e as auferidas pela restante população.

Começando por observar os dados produzidos pelas diferentes instituições académicas, verificamos que, não obstante as discrepâncias vislumbráveis entre elas (disparidades expectáveis, uma vez que as "moratórias" de entrada no mercado de trabalho e as áreas científicas nelas representadas conhecem expressões distintas), duas tendências sobressaem. Em primeiro lugar, é muito baixo o volume de graduados que no momento da inquirição - ou, no caso dos estudos que caracterizam vários momentos de inserção, no último período considerado - auferia uma remuneração líquida inferior a ${ }_{45}^{[\oplus 5} 500$ (limite remuneratório inferior adoptado na maior parte dos estudos). É pois, tudo indica, residual o número dos diplomados que não ultrapassavam a linha do salário mínimo nacional. Segunda tendência: a situação remuneratória vai melhorando de forma nítida nos primeiros anos de inserção, esbatendo-se os patamares remuneratórios inferiores e ampliando-se os mais elevados. Se fixarmos, por exemplo, a fasquia nos ${ }_{45}^{60} 1000^{10}$, e considerarmos apenas os estudos que permitem acompanhar longitudinalmente as trajectórias remuneratórias dos diplomados, apura-se que a porção que se situa acima desse patamar salarial aumenta significativamente à medida que o momento da obtenção do diploma vai ficando mais distante. No estudo do ODES (2002: 36) (que se distingue de todos os outros por contemplar os "rendimentos brutos"), evolui-se de $8,3 \%$ de indivíduos com rendimentos superiores a essa fasquia no primeiro mês após a conclusão do curso para $62,8 \%$ transcorridos 5 anos. Padrão concorrente ressai no estudo levado a cabo na FCSH-UNL (Chaves e Morais, 2008: 27), estudo este que incluiu procedimentos e temporalidades semelhantes embora, diversamente, tenha considerado os "rendimentos líquidos". Aí, dos 9,8\% que auferiam valores superiores a 敬1000 logo no primeiro mês depois da licenciatura concluída 
“salta-se" para 37,2\% aproximadamente 5 anos após a obtenção do grau (o valor de $€ 1000$ líquidos era superado por $16,2 \%$ e $24,5 \%$ no final de, respectivamente, 18 e 36 meses). Estes dados são consistentes com os obtidos para a Universidade de Lisboa (Alves, 2005: 104), que, apesar de contemplar uma temporalidade do percurso de inserção distinta da eleita nos dois estudos anteriores, estabeleceu também como baliza remuneratória "primária" os 韫1000. Nesse estudo, o número de diplomados com remunerações que ultrapassam essa fasquia aumenta de $13,2 \%$ para $34,2 \%$ do "primeiro" para o "último emprego". Este padrão, isto é, a tendência para se verificar uma melhoria progressiva da retribuição remuneratória é ainda notória em qualquer dos restantes estudos que permitem, mesmo com limitações, acompanhar a evolução dos rendimentos (Martins, Arroteia e Gonçalves, 2002: 90; Geraldes e Santos, 2004: 105; Mendes, Patrício e Lucas, 2006: 67; Almeida, Vaz, Marques e Dominguinhos, 2007: 27).

Independentemente dos méritos analíticos que possam ser imputados às regularidades detectadas, o Inquérito ao Emprego do INE (terceiro trimestre de 2010) dilata bastante as potencialidades da análise, uma vez que permite comparar, de forma actualizada, a condição remuneratória dos diplomados com a dos indivíduos sem formação superior, e assim avaliar, em termos relativos, a situação dos primeiros.

Empreendido o cotejo, avulta o contraste remuneratório. Logo desde o primeiro escalão etário (15-24 anos), os rendimentos são, em média, mais elevados na banda dos indivíduos que detêm formação superior (45715) do que no conjunto da população portuguesa na mesma faixa etária (医527). Mesmo aqueles que, nesse arco de idades, se posicionam em segundo lugar - os indivíduos com estudos secundários ou póssecundários - não ultrapassam, em média, os ${ }_{45}^{\text {T5 }} 544$ mensais. O desfasamento acentua-se consideravelmente, sempre em favor dos diplomados, nos escalões etários seguintes: beneficiando de valores médios de 原1026 entre os 25 e os 34 anos, e de 原1 1444 entre os 35 e os 44 anos, os indivíduos com formação superior registam remunerações $40 \%$ e $74 \%$ acima das que são, sempre em média, auferidas pelo conjunto formado pelo total da população empregada nos mesmos intervalos de idade. Com efeito, essas "ficam-se"

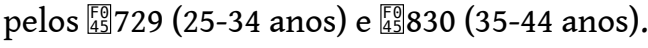

Assim, independentemente de, com base seja em que critério, se poder considerar que os níveis de rendimento dos diplomados são baixos - avaliação negativa que os próprios tendem a emitir quando instados a apreciar a sua situação remuneratória -, o certo é que o seu ascendente remuneratório é, do ponto de vista comparativo, manifesto. Não se trata de uma vantagem específica do nosso país. Além de ser salientada por vários autores (Maurin 2007: 162), encontra-se descrita em diversos relatórios internacionais. A título de exemplo, num relatório recente da OCDE (2009) o desvio remuneratório positivo dos que possuem um diploma do ensino superior supera os 150 pontos (numa base 100) em 17 dos 28 países analisados. 0 que muito provavelmente distinguirá Portugal é o facto de essas diferenças serem ainda mais pronunciadas do que no resto da Europa. Num artigo irónica mas expressivamente intitulado "a trágica fortuna dos licenciados", baseado no Inquérito ao Emprego do INE (no caso datado de 2003), Pedro Portugal (2004: 79-80) anota que "Os vários estudos que estabelecem comparações internacionais dos prémios de licenciatura não divergem na conclusão de que o mercado de trabalho português apresenta prémios invulgarmente elevados. Serão, aliás, os mais elevados da União Europeia", a ponto de se poder afirmar que "o investimento em formação escolar superior oferece, no mercado de trabalho português, uma rentabilidade privada excepcional" (ibidem: 73). o facto é interpretado pelo autor 
como uma consequência do ainda assinalável desfasamento entre a oferta e a procura de qualificações superiores que se verifica no mercado de trabalho nacional. Esse desfasamento que persistirá desde a década de noventa, altura em que as rápidas transformações tecnológicas "pressionaram" a procura de trabalhadores qualificados, terá beneficiado em termos de prémios salariais os indivíduos com maior nível de escolaridade. A menor percentagem de licenciados em Portugal, por comparação com o resto da Europa, e a contínua procura de mais qualificações apontam para a persistência dessa diferenciação (ibidem: 80), embora haja estudos que sugerem a progressiva contracção desse hiato remuneratório (Escária, 2006: 24).

\section{Situação contratual}

Embora tudo indicie que, regra geral, em caso de desemprego os diplomados (particularmente os jovens) (re)ingressam mais facilmente no mercado de trabalho do que os indivíduos que dispõem de recursos escolares inferiores (Gonçalves, C. M. (coord.), 2010), os dados disponíveis não indicam que, no plano dos vínculos contratuais, a situação dos "novos diplomados" seja de vantagem perante os seus parceiros etários. Começando por recuperar o Inquérito ao Emprego do INE (3.ำ trimestre de 2010), constatamos que os "contratos sem termo" - vínculos contratuais que auguram uma maior estabilidade - são bastante menos frequentes entre os indivíduos com ensino superior do que nos restantes níveis de instrução. De facto, dos 15 aos 24 anos só $17,1 \%$ dos indivíduos com títulos superiores celebraram "contratos sem termo", figura que tutela $45,5 \%$ do total da população da citada faixa. No escalão seguinte, 25-34 anos, a diferença diminui mas é ainda significativa: os "contratos sem termo" vigoram para $56,7 \%$ dos graduados, enquanto na população geral compreendem $66,9 \%$. Diante destes valores, nada parece indicar que, ao contrário do que sucede com as três dimensões antes escalpelizadas, os "novos diplomados" sejam comparativamente beneficiados em termos de estabilidade contratual, bem pelo contrário. Porém, estendendo um pouco mais o escopo analítico, é necessário notar que a entrada dos diplomados no mercado de trabalho se faz, regra geral, de forma consideravelmente mais tardia e porventura mais selectiva em termos de procura de emprego. Disso mesmo parece ser indício o facto de nos escalões etários posteriores o peso relativo dos "contratos sem termo", quando opomos diplomados a população geral, se ir progressivamente invertendo: a paridade é atingida na faixa etária dos 35-44 anos (embora já com um ligeiro ascendente dos graduados - os "contratos sem termo" abrangem $84,9 \%$ deles, para $82,2 \%$ do total), mas no escalão etário seguinte já se regista uma clara sobre-representação dos "contratos sem termo" nos graduados.

41 Uma vez que, como já referimos, os estudos realizados pelas diversas instituições do ensino superior cobrem coortes de diplomados díspares, versam períodos de entrada/ permanência no mercado de trabalho distintos e utilizam categorias diversas para descrever os vínculos contratuais, consideramos que, mesmo cumulativamente, os seus dados não são recomendáveis para se proceder a uma leitura de âmbito nacional. Ainda assim, anote-se que os contratos mais estáveis - "contratos sem termo" ou aparentados - oscilam, se excluirmos os dados do ODES, entre um valor mínimo de $24,6 \%$ (na Universidade de Évora) e máximo de 60,9\% (na Escola Superior de Ciências Empresariais em Setúbal). Visto que os diplomados inquiridos se situam entre a metade mais elevada da categoria etária dos 15-24 anos e a parcela mais jovem da categoria dos 25-34 anos, 
os dados parecem ser compatíveis com os que o Inquérito ao Emprego do INE permitiu apurar.

Por que razão excluímos desta leitura o estudo do ODES, perguntar-se-á? A razão é simples. Prende-se ao facto de esses dados (que já datam do início da primeira década do século XXI) identificarem uma prevalência elevada dos "contratos sem termo" nos diplomados (é de $74,9 \%$ volvidos cinco anos após a conclusão da licenciatura) (ODES, 2002: 30). Ora, não cremos que esta prevalência se mantenha, mormente em virtude da progressiva precarização das modalidades de vinculação laboral firmada ao longo da década, sobretudo no atinente aos primeiros anos de ingresso no mercado de trabalho. Tratar-se-á assim de um dado especialmente desactualizado, que por essa razão propositadamente descartamos.

O que podemos afirmar com segurança é que a precarização contratual se tem vindo a acentuar consideravelmente em Portugal na última década, particularmente junto dos segmentos juvenis (Oliveira e Carvalho, 2008). De tal forma que, em 2009 (Dornelas, 2011: 26), a percentagem de trabalhadores com "contratos a termo" atingia entre nós valores em torno dos $22 \%$, enquanto a média da UE27 se cifrava em $13,5 \%{ }^{11}$.

Se a precarização contratual se intensificou mais entre os diplomados do que noutras populações é matéria a explorar noutro momento. É no entanto lícito pôr a hipótese de que a dificuldade de obter um vínculo contratual mais estável terá, junto dos diplomados, efeitos mais exasperantes, uma vez que recobrirá estádios mais avançados do curso de vida, curto-circuitando as várias dimensões em que se joga o processo de transição para a vida adulta, com destaque para a "estabilização da autarcia económica" face à família de origem, aspecto cuja importância, para a estruturação de um estilo de vida autónomo mas também para a avaliação de si mesmo, nos deteve demoradamente noutra circunstância analítica (Chaves, 2010: 281-92 e 388-89).

Antes de prosseguirmos, cremos ser conveniente abrir aqui um parêntesis com o propósito de deixar claro que a precarização dos vínculos contratuais é percepcionada pela ampla maioria dos diplomados como uma adversidade a evitar; inversamente, a estabilidade e a segurança no trabalho são tidas como condições do trabalho desejáveis e a conquistar (Morais, Chaves e Batista, 2010: 249). Tais atitudes são aliás partilhadas pela maioria da população portuguesa (Freire, 2000, 2008; Vala, 2000; Oliveira e Carvalho, 2008: 556-557) e europeia, embora com diferenças e nuances nacionais não desprezíveis, bem documentadas por Oliveira e Carvalho (2008). Dir-se-ia, por outras palavras, que, apesar dos seus eventuais impactos, a crescente exposição ao discurso ideológico contido no "modelo da competência" (Boltanski e Chiapello, 1999) não parece ter sido suficiente para promover a naturalização dos vínculos precários, e menos ainda para inscrever, junto da maioria, a crença na precariedade como algo exaltante, honroso, formativo, resumidamente, a crença numa "precariedade identificante", para convocar a feliz expressão de Dubar (2000: 216), já antes usada por Dubet (1996). Isto não significa que não encontremos em Portugal determinados sectores de assalariados com um nível de instrução superior onde uma relação mais indulgente ou optimista com a instabilidade é (já) uma realidade. A título de exemplo, num estudo sobre jovens licenciados em engenharias A. P. Marques (2002) verificou que, entre estes, a precariedade e a flexibilidade são encaradas como situações típicas do mercado de trabalho actual e, por vezes, procuradas voluntariamente. Algumas novas formas de trabalho e os vínculos contratuais instáveis deixam de ser vistos como constrangimentos, passando a ser considerados recursos mobilizáveis na construção de 
carreiras profissionais. Estaremos então perante verdadeiras disposições à precariedade, cuja valência, expansão ou contracção empíricas importa não descurar.

\section{Da "desilusão colectiva"}

Uma outra pré-noção comummente difundida, assinalada com destaque no início do artigo, é a de que se verifica uma extensa e marcada "desilusão colectiva" no corpo global dos diplomados portugueses com o seu destino profissional e, dessa forma, retrospectivamente, com o patamar académico e/ou com a área disciplinar em que se formaram. Esse desalento, que afectaria sobretudo os graduados de determinadas áreas, como por exemplo as ciências sociais e comportamentais ou o Direito, seria, num primeiro momento, resultante do defraudar das expectativas de mobilidade social e, concomitantemente, de obtenção de recompensas remuneratórias e estatutárias ajustadas ao patamar escolar alcançado, expectativas induzidas pelo próprio sistema de ensino e favorecidas pela proximidade temporal de um estádio precedente no qual haviam sido de facto cumpridas (Alves, 2008: 283; Grácio, 1997: 508). A tese das expectativas goradas que instaurariam, em parte dos casos, um sentimento de burla e traição naqueles que as vivenciam tem antecedente desde a década de 1960 no próprio pensamento sociológico, com destaque para as obras de Bourdieu e Passeron (1966; 1970), encontrando-se plasmada na utilização de termos que fizeram escola, como o de "geração enganada" (Nogueira e Nogueira, 2002: 17). Nos dias que correm, a este desencanto viria somar-se o provocado pelo desemprego e, talvez mais decisivo ainda, pela diluição da homologia estrutural entre capital escolar e capital profissional.

Não querendo colocar aqui totalmente em questão o valor heurístico da tese do sentimento de desilusão colectiva, e menos ainda o pressuposto da experiência anómica que lhe subjaz, é forçoso verificar que mais uma vez estes têm de ser encarados com precaução no cotejo com os dados empíricos. Constatamos que grande parte da informação produzida acerca dos diplomados portugueses não os sustenta, muito pelo contrário. E nem podemos falar de singularidade portuguesa. Uma consulta aos dados apresentados por Storen e Arnesen (2007: 257-58) alinha, nesta matéria, os diplomados portugueses com os da generalidade dos outros países europeus, pelo menos dos que integraram o projecto REFLEX.

Seria com efeito expectável que, no caso de se impor de forma ampla e aguda, o sentimento de desilusão transparecesse, sem peias, na avaliação que os diplomados fazem a) quer do grau de ajustamento da sua formação à situação profissional (emprego) em que se encontram; b) quer, em termos gerais, da sua situação profissional. Tal não se verifica nem num caso nem no outro. Relativamente ao primeiro aspecto, já atrás elucidámos que, embora a percepção desse ajustamento varie de curso para curso, uma clara maioria dos jovens diplomados portugueses afirma que a sua actividade profissional se adequa à sua área de formação (Alves, 2005; Geraldes e Santos, 2004; ODES, 2002; Chaves e Morais, 2008).

Quanto ao segundo aspecto, os dados, particularmente os gerados acerca dos níveis de satisfação, indicam que a avaliação é bastante mais positiva do que a tese da decepção abrangente permitiria prever. São três os estudos que publicitam informações sobre os níveis de satisfação, pelo que por eles principiaremos. Detendo-nos de novo no estudo ODES (2002: 52), verificamos que 59,5\% se revelaram "satisfeitos" com o "percurso profissional" e 27,3\% "muito satisfeitos"; apenas $12,8 \%$ se afirmaram "pouco" ou "nada 
satisfeitos". Em Aveiro (Martins, Arroteia e Gonçalves, 2002: 108), a média de satisfação com a "situação profissional actual" é de 4 numa escala de 6 valores. No inquérito mais recente, centrado em licenciaturas das ciências sociais e humanas (Chaves e Morais, 2008: 38), quando questionados acerca do grau de satisfação que experienciam no seu trabalho actual, utilizando uma escala de 1 a 10,72,2\% posicionam-se acima do patamar 6, superando os $20 \%$ a porção que se inscreve nos dois valores mais elevados da escala: 9 e 10 .

50 No estudo da Universidade de Lisboa (Alves, 2005: 153) a avaliação dos níveis de "satisfação com o trabalho actual" também está presente, mas, nesse caso, repartida por diversos temas. É cotada como satisfatória ou completamente satisfatória a "relação com os colegas" $(90,8 \%)$, a "utilidade social" $(89,9 \%)$, o "interesse da actividade" $(88,3 \%)$, a "autonomia de que se dispõe" $(79,1 \%)$ e o "horário de trabalho" $(78,4 \%)$; reunindo ainda a satisfação (completa ou não) de mais de metade dos inquiridos, embora já em claro plano descendente, o "acesso à formação contínua" (62,6\%), a "estabilidade" (52,4\%) e o "nível de remuneração" (50,7\%); as "oportunidades de promoção" $(44,8 \%)$ constituem o aspecto menos satisfatório. Voltaremos ao conteúdo destas avaliações parcelares mais adiante, a fim de sondar as razões que estão na base da avaliação tendencialmente positiva com que deparamos na totalidade dos estudos.

51 No trabalho que envolveu as diversas escolas algarvias (Geraldes e Santos, 2004: 107), a questão posta aos diplomados concitava de novo uma avaliação abrangente mas, agora, polarizada na "concretização das expectativas profissionais". Perguntava-se, em concreto, "em relação às suas expectativas como avalia globalmente a sua actividade profissional". Além dos $56,6 \%$ que garantiram que o referido enquadramento correspondeu ao esperado, 14,2\% mencionaram que "excedeu" e $2 \%$ que "excedeu muito".

52 Em virtude de colidir com pré-noções muito estabelecidas, a expressão quantitativa das avaliações positivas gera estupefacção e justifica profundas análises futuras no sentido de deslindar o seu significado. É todavia possível avançar hipóteses interpretativas, resultado de reflexões e investigações por nós anteriormente conduzidas. Em parte, cremos que ela se ficará a dever directamente aos aspectos assinalados no primeiro ponto: o número de diplomados que estimam que o mercado de trabalho lhes proporciona recompensas económicas e estatutárias “justas" ou pelo menos satisfatórias e que consideram a sua situação profissional conforme ao nível e teor da sua formação superior é afinal significativo, maior do que geralmente se presume.

53 Mas a este elemento explicativo sobrepor-se-á um outro, tanto mais digno de menção quanto até hoje passou analiticamente despercebido. Achem ou não que a sua situação profissional presente materializa as suas aspirações, os diplomados entendem, na sua larga maioria, que o seu trabalho (emprego) lhes permite concretizar um conjunto de gratificações intrínsecas, como sejam a de "obterem prazer com aquilo que fazem", "aplicarem os seus conhecimentos" e "aprenderem coisas novas". Em muitos casos, estes aspectos do trabalho são tanto ou mais valorizados quanto as dimensões extrínsecas - "remuneração elevada", "promoção", "estatuto hierárquico", etc. -, permitindo dessa forma atenuar a sua falta.

54 Esta última interpretação põe também ela em causa o modo como as aspirações dos diplomados face ao trabalho, mas também perante a escola, são equacionadas por grande parte dos observadores, em particular pelos que sustentam as teses da "desilusão colectiva". Com efeito, estes tendem a conferir uma excessiva (senão 
exclusiva) importância aos aspectos extrínsecos (Herzberg et al., 1959; Johnson, 2002; Caetano et al., 2003; Herzog, 1982; Vala, 2000; Loscocco, 1989; Loscocco e Kalleberg, 1988; Marini et al., 1996; Rokeach, 1973). Os diplomados, particularmente os atingidos pela "desilusão colectiva", encontrar-se-iam perante a academia e o mundo profissional movidos sobretudo (ou apenas) segundo princípios de mobilidade social e focados na obtenção de capitais económicos e sociais, e nas formas de capital simbólico em que esses tipos de capital se transmudam. Nesse contexto, para esses diplomados o título académico deteria um valor quase apenas instrumental, esvaziando-se se "para tal não servisse", leia-se não servisse para prosseguir os fins extrínsecos sediados nas esferas da vida profissional, da acumulação económica e do reconhecimento estatutário. A escola estaria pois totalmente "dominada pela sua função de distribuição e pelo reino da utilidade escolar" (Dubet, 2006: 53), basicamente encerrando processos de mobilidade social ascendente.

Ora os dados disponíveis vão na direcção oposta. Mostram que a concretização de recompensas intrínsecas (Herzberg et al., 1959; Johnson, 2002; Caetano et al., 2003; Herzog, 1982; Vala, 2000; Loscocco, 1989; Loscocco e Kalleberg, 1988; Marini et al., 1996; Rokeach, 1973) tem uma relevância assinalável nas aspirações que a grande maioria dos diplomados portugueses acalenta tanto face ao ensino superior como ao trabalho.

No relatório ODES (2002), por exemplo, vê-se que as razões mais aludidas para justificar o ingresso no ensino superior são "estudar e adquirir mais conhecimento" e "poder desempenhar a profissão mais desejada". Qualquer destes motivos é mais prezado do que aumentar as "possibilidades de encontrar um emprego bem remunerado" ou tão-só o de "encontrar um emprego". Essa hierarquização de razões para se aceder ao ensino superior atravessa todas as áreas científicas.

Esta radicação em razões intrínsecas vem porém a registar o seu ponto mais elevado num estudo centrado exclusivamente em mestres e doutores que, na sua maioria, se encontravam já a trabalhar (Alves et al., 2008: 14)12. Aí os motivos "adquirir mais conhecimentos" e "contribuir para o desenvolvimento intelectual" prevalecem nitidamente sobre o repertório que desdobra a procura de vantagens profissionais "encontrar emprego"; "manter emprego"; "mudar de emprego"; "encontrar emprego bem remunerado", ou mesmo "progredir na carreira profissional".

Ao contrário do que sucede com os motivos de ingresso no ensino superior, os dados acerca dos aspectos que os diplomados valorizam no trabalho são raros. Ainda assim, é possível encontrar referências a estas dimensões, por exemplo, no estudo realizado sobre as escolas do ensino superior no Algarve (Geraldes e Santos, 2004), onde se tornou patente a importância que os graduados conferem aos aspectos mais intrínsecos ligados à ocupação profissional: $80 \%$ dos inquiridos consideraram que "ter um trabalho que dê gosto realizar" era o valor mais importante, seguido de um "trabalho que permita desenvolver capacidades" (25\%) - só depois surge um valor mais extrínseco, considerado por cerca de $20 \%$ como o mais importante: "segurança e estabilidade".

No estudo realizado na FCSH-UNL (Chaves e Morais, 2008) também se entrou em linha de conta com estes aspectos, conferindo-lhes, aliás, destaque. Nele procurou-se apurar, mediante uma escala de 10 valores, a relevância que os diplomados em ciências sociais e humanas atribuíam a diversos aspectos do trabalho, a saber: "emprego seguro e estável”; "remuneração elevada"; “oportunidades de promoção"; "autonomia financeira face aos pais"; "trabalho interessante"; "trabalho em que a pessoa tenha autonomia"; "trabalho que permita ajudar outras pessoas"; "trabalho útil à sociedade"; 
"trabalho que permita decidir horários e dias de trabalho". Como resultado, o "trabalho interessante" (isto é, um "trabalho não rotineiro" que permita "aprender coisas novas", "usar as capacidades e competências pessoais" e "ser criativo") sobreveio como um item muito mais valorizado do que "emprego seguro e estável" ou "remuneração elevada".

Esta tendência de sobrevalorização relativa dos aspectos intrínsecos do trabalho - um "trabalho interessante" - face aos valores extrínsecos - "remuneração elevada" ou mesmo "estabilidade" - já fora por nós detectada e analisada em estudos anteriores, também eles realizados junto de populações de diplomados, designadamente de jovens licenciados em Direito que haviam concluído o estágio profissional (Chaves, 2010). Nessa população, essa sobrevalorização verifica-se aliás de forma transversal patenteia-se tanto entre os que converteram o capital académico em capital profissional e económico de grandeza homóloga como nos que enfrentam inserções profissionais precárias.

61 A relevância que os diplomados conferem aos elementos intrínsecos do trabalho e do ensino superior, acompanhada pela crença de que esses elementos são de facto experienciados nas suas situações concretas de trabalho, é, em suma, a nosso ver, essencial para compreender por que razão os sentimentos de desilusão face às experiências laboral e formativa não eclodem afinal, no plano subjectivo, com a intensidade que eventualmente se esperaria se nos limitássemos a ter em conta o putativo estreitamento das oportunidades de mobilidade ou de capitalização económica de que os diplomados gozam no momento actual e a consciência dessa contracção.

É certo que a importância que os indivíduos atribuem aos aspectos intrínsecos do trabalho e os proveitos intrínsecos que dele consideram extrair não são geralmente tomados em devida consideração na análise sociológica, mas não é menos certo que eles apenas poderão surpreender os menos familiarizados com os dados produzidos acerca das dimensões que as pessoas valorizam nas actividades laborais. Tanto em Portugal (Cabral, Vala e Freire (orgs.), 2000; Freire (coord.), 2000; Pais (coord.), 1999), como noutros países (Baudelot e Gollac, 2003; Twenge, Campbell, Hoffman e Lance, 2010) ${ }^{13}$ os dados que o comprovam são já abundantes, evidenciando, além disso, que a valorização dos aspectos intrínsecos tende a aumentar com o acréscimo dos níveis de instrução (Borges e Pires, 1998) e, de um modo mais geral, com a expansão dos valores pósmaterialistas nas sociedades contemporâneas (Inglehart, 1977; 1990; 1997), não obstante o recuo que estes possam ter sofrido no período mais recente, marcado por uma forte depressão e instabilidade económica.

\section{Conclusão}

63 Neste texto tratámos de refutar duas teses entrançadas uma na outra que integram o senso comum sobre o valor dos diplomas académicos e os seus detentores, a saber: a) que tais diplomas, regra geral, hoje em dia pouco valem no mercado profissional, forçando quem os detém a conhecer uma de duas situações típicas: desemprego ou empregos/trabalhos "abaixo" da sua "elevada" condição escolar; b) que os possuidores desses diplomas, penalizados pela sucessão de experiências profissionais frustrantes (incluindo o desemprego e as baixas remunerações), seriam dominados pelo sentimento de desalento (e mesmo pela vontade de retaliação) em relação quer à escola quer ao destino profissional que, contingentemente, lhes coube em sorte. 
64 este par de teses. Não, com efeito não é verdade: 1) que o desemprego qualificado seja em termos absolutos muito expressivo - é aliás reduzido quando se introduz na caracterização da situação dos diplomados perante o mercado de trabalho a abordagem longitudinal para captar as trajectórias de inserção profissional; 2) que o desemprego qualificado seja em termos relativos mais sentido - os dados mostram que, seja qual for a "frente" considerada (emprego, remuneração, etc.), o sobreinvestimento académico compensa; 3) que os diplomados estejam muito expostos à desclassificação social constata-se uma homologia estrutural entre o nível de formação e a categoria socioprofissional - ou que "tenham de aceitar tudo" - pelo menos tanto quanto os próprios testemunham o "desajustamento horizontal" é mais a excepção do que a regra nos processos de inserção profissional, mesmo nas áreas científicas mais sensíveis aos constrangimentos do mercado de trabalho (se se quiser, menos capitalizadas); 4) que o desalento, a decepção e a desilusão sejam tendências dominantes na relação dos diplomados com a escola e o trabalho. Se outro mérito não tivesse, esta última "descoberta" obriga-nos aliás a não descurar a importância analítica que os aspectos intrínsecos adquirem no confronto dos diplomados com o mundo profissional mas também, a montante deste, com o próprio ensino superior, mormente na escolha de cursos ou áreas de conhecimento. Fazemos pois nossas as palavras de Bourdieu quando refere, ao chamar a atenção para estes aspectos, que quanto mais nos afastamos do "trabalho forçado, que é determinado exclusivamente pela imposição externa (...) menos se trabalha directamente por dinheiro e mais cresce o 'interesse' do trabalho, a gratificação inerente ao facto de se realizar o trabalho - bem como o interesse ligado aos ganhos simbólicos associados ao nome da profissão ou ao estatuto profissional e à qualidade das relações de trabalho que acompanham muitas vezes o interesse intrínseco do trabalho" (Bourdieu, 1998 [1997]: 180).

Regressando contudo ao cerne do argumento, diríamos, para finalizar, que, não sendo difícil prever que a situação dos diplomados perante o trabalho, dada a contracção significativa que a economia portuguesa conhecerá nos próximos anos, se deteriorará, isso não confere razão retrospectiva às alegações catastrofistas que permearam as representações vulgares - sobretudo as mediáticas - nas últimas duas décadas acerca da situação dos diplomados portugueses. Até hoje essas teses não resistiram ao teste empírico sério que pauta o modo de conhecer das ciências sociais; modo que, é bom não esquecer, exige a sua própria actualização, gerando nova prova empírica mas também a identificação e explicação das relações e processos sociais que nela se enredam. Aferir o grau de depreciação do valor material e simbólico dos títulos académicos, em termos absolutos mas também relativos (por comparação com diplomas "inferiores"), é e será sempre, na restituição científica, matéria para apuramento empírico rigoroso, pouco compatível com as digressões dramáticas e sensacionalistas que frequentemente compõem o mundo da notícia e da opinião. 


\begin{tabular}{|c|c|c|c|c|c|c|}
\hline Autores & Âmbito do Estudo & $\begin{array}{c}\text { Ano } \\
\text { de } \\
\text { publicaçăo }\end{array}$ & $\begin{array}{c}\text { Ano } \\
\text { de } \\
\text { dinquiriçāo }\end{array}$ & $\begin{array}{l}\text { Ano de conclusăo } \\
\text { de curso } \\
\text { dos inquiridos }\end{array}$ & Universo/ Amostra & $\begin{array}{l}\text { Margem de erro/ } \\
\text { Representatividade }\end{array}$ \\
\hline 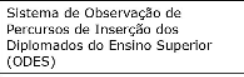 & $\begin{array}{l}\text { Licenciados do ensino superior em } \\
\text { Portugal }\end{array}$ & 2002 & 2001 & $1994 / 95$ & $\mathrm{~N}=31.000 / \mathrm{n}=10.000$ & Amostra cobre $32 \%$ do universo \\
\hline Maria Geraldes e Paulo Santos & $\begin{array}{l}\text { Licenciados no Algarve } \\
\text { (U. Algarve, Instituto Superior } \\
\text { de Matemática Gestăo } \\
\text { e Institutu Superior D. Afonso III) }\end{array}$ & 2004 & 2003 & 1999 a 2001 & $N=3.998 / n=426$ & Amostra cobre $11 \%$ do universo \\
\hline $\begin{array}{l}\text { António Martins, Jorge Arrotela } \\
\text { e Maria Manuela Gonsalves }\end{array}$ & Licenclados da U. Aveiro & 2002 & 2001 & 1995/96 a 1999/00 & $\mathrm{N}-3.372 / \mathrm{n}-1.191$ & Amostra cobre $35 \%$ do universo \\
\hline $\begin{array}{l}\text { Carlos Vieira, Luís Raposo } \\
\text { e Maruela Santos }\end{array}$ & Licenciados da U. Évora & 2008 & 2007 & $2001 / 02$ a 2005/06 & $N=3.664 / n=871$ & Amostra cobre $24 \%$ do universo \\
\hline Natália Alves & Licenciados da U. Lisboa & 2005 & 2005 & 1999 a 2003 & $N=8.107 / n=2.216$ & Armostra cobre $27 \%$ do universo \\
\hline Albertino Gonçalves & Licenclados da U. Minho & 2001 & 1997-1998 & 1990 a 1994 & $N=1.018 / n=764$ & Amostra cobre $75 \%$ do universo \\
\hline $\begin{array}{l}\text { Carlos Goncalves, Isabel Menezes } \\
\text { e Maria Martins }\end{array}$ & Licenciados da U. Porto & 2009 & 2009 & $2006 / 07$ & $\mathrm{~N}=3.025 / \mathrm{n}=1.642$ & Amostra cobre $54 \%$ do universo \\
\hline Sandra Saúde & Licenciados do P. Beja & 2005 & 2004 & $2000 \div 2003$ & $N=1.956 / n=528$ & Amostra cobre $27 \%$ do universo \\
\hline $\begin{array}{l}\text { António Jasé Alrneida, Isabel Faria } \\
\text { Vaz, M. . A Amélla Marques } \\
\text { e Pedro Dominguinhos. }\end{array}$ & Licenciados do P. Setúbal & 2007 & $2006-2007$ & 2000 a 2006 & $\mathrm{~N}=1080 / \mathrm{n}=464$ & Amostra cobre $43 \%$ do universo \\
\hline Miguel Chaves e César Morais & $\begin{array}{l}\text { Licenciados da F. Ciências Sociais } \\
\text { e Humanas da U. Nova Lisboa }\end{array}$ & 2008 & 2007 & 2001 a 2002 & $N=601 / n=236$ & $\begin{array}{l}\text { Margem de erro de 5\% para um } \\
\text { intervalo de confiança de } 95 \%\end{array}$ \\
\hline $\begin{array}{l}\text { Rui Mendes, João Patricio } \\
\text { e Ana Lucas }\end{array}$ & $\begin{array}{l}\text { Licenciados do Instituto Superior } \\
\text { Técnico }\end{array}$ & 2006 & $2005 / 6$ & 2002 a 2005 & $\mathrm{~N}=2.914 / \mathrm{n}=646$ & Amostra cobre $22 \%$ do universo \\
\hline
\end{tabular}

\section{BIBLIOGRAFIA}

INSTITUTO NACIONAL DE ESTATÍSTICA (2010), Inquérito ao Emprego - 3.ำ Trimestre, Lisboa, INE.

ALLEN, J. e R. Van der Velden (edits.) (2007), Research into Employment and Professional Flexibility, Maastricht, Research Centre for Education and the Labour Market.

ALMEIDA, A. J.; I. F. Vaz; M. Marques e P. Dominguinhos (2007), Inserção profissional dos licenciados pela ESCE: relatório do inquérito realizado em 2006/2007, Setúbal, Escola Superior de Ciências Empresariais/IPS.

ALVES, M. G. (2003), A Inserção Profissional de Diplomados do Ensino Superior Numa Perspectiva Educativa: o Caso da Faculdade de Ciências e Tecnologia, Tese de Doutoramento, Faculdade de Ciências e Tecnologia da Universidade Nova de Lisboa.

ALVES, M. G. (2004), "Os Diplomados do ensino superior: diferenciação sexual nos processos de inserção profissional”, Sociologia, Vol. 14, pp. 227-251.

ALVES, M. G. (2007), A Inserção Profissional de Diplomados do Ensino Superior numa Perspectiva Educativa: o caso da Faculdade de Ciências e Tecnologia, Lisboa, Fundação Calouste Gulbenkian.

ALVES, M. G. (2009), "Entre o ensino superior e a inserção profissional - análise comparativa de percursos de diplomados”, em M. C. Silva e outros, Livro de Actas do X Congresso Luso-Afro-Brasileiro de Ciências Sociais (Vol. III), pp.108-115.

ALVES, M. G. (2010), “A inserção profissional de graduados em Portugal: notas sobre um campo de investigação em construção”, em A. P. Marques e M. G. Alves (orgs.), Inserção profissional de graduados em Portugal: (re)configurações teóricas e empíricas, Braga, Húmus, pp. 31-50.

ALVES, M. G. et al. (eds.) (2008), Universidade e Formação ao Longo da Vida, Oeiras, Celta.

ALVES, N. (1998), "Escola e trabalho: atitudes, projectos e trajectórias", in M. V. Cabral e J. M. Pais, Jovens Portugueses de Hoje: Resultados do Inquérito de 1997, Oeiras, Celta, pp. 53-134. 
ALVES, N. (2000), Trajectórias Académicas e de Inserção Profissional dos Licenciados pela Universidade de Lisboa 1994-1998, Lisboa, Universidade de Lisboa.

ALVES, N. (2005), Trajectórias Académicas e de Inserção Profissional dos Licenciados pela Universidade de Lisboa 1999-2003, Lisboa, Universidade de Lisboa.

ALVES, N. (2008), Juventudes e Inserção Profissional, Lisboa, Educa.

ALVES, N.; M. Centeno e Á. Novo (2010), “O investimento em educação em Portugal: retornos e heterogeneidade”, Boletim Económico do Banco de Portugal, 16 (1), pp. 9-39.

BAUDELOT, C. e M. Gollac (2003), Travailler pour être heureux. Le Bonheur et le travail en France, Paris, Fayard.

BOLTANSKI, L. e È. Chiapello (1999), Le Nouvel esprit du capitalisme, Paris, Gallimard.

BORGES, G. C. e L. Pires (1998), “Escola, trabalho e emprego”, em J. M. Pais (coord.), Gerações e Valores na Sociedade Portuguesa Contemporânea, Lisboa, SEJ/ICS, pp. 247-318.

BOURDIEU, P. (1979), La distinction: critique sociale du jugement, Paris, Les Éditions de Minuit.

BOURDIEU, P. (1998 [1997]), Meditações Pascalianas, Oeiras, Celta.

BOURDIEU, P. e J.-C. Passeron (1966), Les Héritiers. Les étudiants et la culture, Paris Les Éditions de Minuit.

BOURDIEU, P. e J.-C. Passeron (1970), La Reproduction. Eléments pour une théorie du système d'enseignement, Paris, Les Éditions de Minuit.

BOURDIEU, P. e P. Champagne (1993), “Les exclus de l'intérieur”, La misère du monde, Paris, Seuil. CABRAL, M. V.; J. Vala e J. Freire (orgs.) (2000), Trabalho e Cidadania, Lisboa, Imprensa de Ciências Sociais.

CABRITO, B. G. (2008), "Educação de adultos e aprendizagem ao longo da vida: experiências de pós-graduação" in M.G. Alves et al., Universidade e Formação ao Longo da Vida, Oeiras, Celta, pp. 91-114.

CAETANO, A. et al. (2003), "Valores do trabalho em Portugal e na União Europeia", em J. Vala, M. V. Cabral e A. Ramos (orgs.), Valores Sociais: Mudanças e Contrastes em Portugal e na Europa, Lisboa, Imprensa de Ciências Sociais, pp. 430-457.

CANÁRIO, R. (2008), “A Escola: das “promessas' às ‘incertezas””, Educação Unisinos, 12(2), pp. 73-81.

CHAVES, M. (2010), Confrontos com o Trabalho entre Jovens Advogados. As novas configurações da inserção profissional, Lisboa, Imprensa de Ciências Sociais.

CHAVES, M. e C. Morais (2008). Relatório sobre o percurso dos licenciados da FCSH-UNL que concluíram os cursos no ano 2002, Lisboa, FCSH-UNL.

DORNELAS, A. (2011), Emprego, contratação colectiva de trabalho e protecção da mobilidade social em Portugal, Lisboa, Gabinete de Estratégia e Planeamento: Ministério do Trabalho e da Solidariedade Social.

DUARTE, A. (2008), “Trabalho, flexibilidade e precariedade no contexto europeu: precisões analíticas e evidências empíricas", Cadernos de Ciências Sociais, 25-26, pp. 1-51.

DUBAR, C. (2000), La Crise des identités. L'interprétation d'une mutation, Paris, PUF.

DUBET, F. (2006), Injustices. L’Expérience des inégalités au travail, Paris, Seuil. 
ESCÁRIA, V. (coord.) (2006), Percursos de inserção no mercado de trabalho dos diplomados do Ensino Superior, Lisboa, Gabinete de Estratégia e Planeamento: Ministério do Trabalho e da Solidariedade Social.

FREIRE, J. (coord.) (2000), Atitudes face ao Emprego, Trabalho e Tempo Livre - Os Processos de Motivação para o Trabalho, Lisboa, Observatório do Emprego e Formação Profissional.

FREIRE, J. (coord.) (2008), Orientações perante o Trabalho e Relações Laborais, Relatório Final, Lisboa, ICS/MTSS.

GALLAND, O. (1991), Sociologie de la jeunesse, Paris, Armand Colin.

GERALDES, M. e P. Santos (2004), A Inserção Profissional dos Jovens Diplomados do Algarve, Faro, Fundação da Juventude.

GONÇALVES, A. (2001), As asas do diploma - a inserção profissional dos licenciados pela Universidade do Minho, edição do Grupo de Missão para a Qualidade do Ensino/Aprendizagem da Universidade do Minho, Braga, Universidade do Minho.

GONÇALVES, C. M. (coord.) (2010), Licenciados, Precariedade e Família, Porto, Estratégias Criativas.

GONÇALVES, C.; I. Menezes e M. Martins (2009), Transição para o trabalho dos licenciados da Universidade do Porto (2005-2006), Porto, Universidade do Porto.

GONÇALVES, F.; T. Carreira; S. Valadas e B. Sequeira (2006), "Percursos de Empregabilidade dos Licenciados: perspectivas europeias e nacional”, Análise Psicológica, 24, pp. 99-114.

GRÁCIO, S. (1997), Dinâmicas da Escolarização e das Oportunidades Individuais. Lisboa, EDUCA Formação.

HERZBERG, F. et al. (1959), The Motivation to Work. Nova Iorque, John Wiley and Sons.

HERZOG, A. R. (1982), "High school seniors occupational plans and values - Trends in sex differences 1976 through 1980", Sociology of Education, 55, pp. 1-13.

INGLEHART, R. (1977), The Silent Revolution. Changing Values and Political Styles Among Western Publics, Princeton, Princeton University Press.

INGLEHART, R. (1990), Culture Shift in Advanced Industrial Societies, Princeton, Princeton University Press.

INGLEHART, R. (1997), Modernization and Post-Modernization. Value Change in 43 Societies, Princeton, Princeton University Press.

JOHNSON, M. K. (2002), "Social origins, adolescent experiences and work value trajectories during the transition to adulthood", Social Forces, 80 (4), pp.1307-1341.

LOSCOCCO, K. A. (1989), “The instrumentally oriented factory worker, myth or reality?”, Work and Occupations, 161, pp. 3-25.

LOSCOCCO, K. A. e A. L. Kalleberg (1988), “Age and the meaning of work in the United States and Japan", Social Forces, 67 (2), pp.337-355.

MARINI, M. M. et al. (1996), “Gender and job values”, Sociology of Education, 69, pp. 49-65.

MARQUES, A. P. (2002), Entre o Diploma e o Emprego: a Inserção Profissional de Jovens Engenheiros, Porto, Afrontamento.

MARQUES, A. P. e M. G. Alves (orgs.) (2010), Inserção profissional de graduados em Portugal: (re)configurações teóricas e empíricas, Braga, Húmus. 
MARTINS, A.; J. Arroteia e M. Gonçalves (2002), Sistemas de (des)emprego: trajectórias de inserção, Aveiro, Universidade de Aveiro.

MAURIN, É. (2007), La nouvelle question scolaire. Les bénéfices de la démocratisation, Paris, Seuil.

MENDES, R.; J. Patrício e A. Lucas (2006), III Inquérito ao percurso sócio-profissional dos diplomados do IST, Lisboa, IST.

MORAIS, C.; M. Chaves e S. Batista (2010), "Notas sobre o estudo da precariedade e dos confrontos subjectivos com a precariedade entre os diplomados de uma faculdade de ciências sociais e humanas", em A. P. Marques e M. G. Alves (orgs.) (2010), Inserção profissional de graduados em Portugal. (Re)configurações teóricas e empíricas, Braga, Húmus, pp. 233-258.

NICOLE-DRANCOURT, C. e L. Roulleau-Berger (2001), Les jeunes et le travail: 1950-2000, Paris, PUF. NOGUEIRA, C. M. e M. A. Nogueira (2002), «A sociologia da educação de Pierre Bourdieu: limites e contradições», Educação \& Sociedade, Ano XXII, N.7 78, pp. 15-36.

NUNES, J. S. (2011), "Da(s) diferença(s) escolar(es): lógica da acção e regimes de envolvimento”, Actas electrónicas do II Encontro de Sociologia da Educação - "Educação, Territórios e (Des)Igualdades", Faculdade de Letras da Universidade do Porto, 27 e 28 de Janeiro de 2011, pp. 589-597.

ODES - Sistema de Observação de Percursos de Inserção de Diplomados do Ensino Superior (2002), Inquérito de Percurso aos Diplomados do Ensino Superior: Síntese de Resultados, Lisboa, Instituto para a Inovação na Formação.

OLIVEIRA, L. e H. Carvalho (2008), “A precarização do emprego na Europa”, DADOS - Revista de Ciências Sociais, 3/51, pp. 541-567.

PAIS, J. M. (coord.) (1999), Gerações e Valores na Sociedade Portuguesa Contemporânea, Lisboa, SEJ/ICS. PETITAT, A. (1994), Produção da escola, produção da sociedade, Porto Alegre, Artes Médicas.

PORTUGAL, P. (2004), "Mitos e factos sobre o mercado de trabalho português: a trágica fortuna dos licenciados”, Boletim Económico do Banco de Portugal, Março, pp. 73-80.

ROKEACH, M. (1973), The Nature of Human Values, Nova Iorque, MacMillan.

SAÚDE, S. (2005), Percursos de Inserção Profissional dos Diplomados do Ensino Superior Politécnico, Beja, Instituto Politécnico de Beja.

SHOMBURG, H. e U. Teichler (2006), Education and Graduate Employment in Europe, Dordrecht, Springer.

STOREN, L. A. e C. A. Arnesen (2007), “Winners and Losers”, em J. Allen e R. Van der Velden (eds.), The Flexible Professional in the Knowledge Society: General Results of the REFLEX Project, The Netherlands, Research Centre for Education and the Labour Market, University of Maastricht.

TEICHLER, U. (ed.) (2007), Careers of University Graduates: Views and Experiences in Comparative Perspectives, Dordrecht, Springer.

TWENGE, J.; S. Campbell; B. Hoffman e C. Lance (2010), “Generational Differences in Work Values: Leisure and Extrinsic Values Increasing, Social and Intrinsic Values Decreasing", Journal of Management, 36(5), pp. 1117-1142.

VALA, J. (2000), "Mudanças nos valores associados ao trabalho e satisfação com o trabalho", em M. Villaverde Cabral, J. Vala e J. Freire (orgs.), Trabalho e Cidadania, Lisboa, Imprensa de Ciências Sociais, pp.73-95. 
VIEIRA, C.; L. Raposo e M. Santos (2008), Relatório sobre o Inquérito aos Licenciados da Universidade de Évora, Évora, Pró-Reitoria para a Política da Qualidade e Inovação.

\section{NOTAS}

1. São considerados neste estudo os diplomados da Universidade do Algarve (única instituição de Ensino Superior Público na região), dos Institutos Superiores de Matemáticas e Gestão e de Humanidades e Tecnologias (Grupo Lusófona), do Instituto Superior Dom Afonso III e da Escola Superior de Saúde Jean Piaget.

2. Em certos momentos do texto convocar-se-ão outros contributos, devidamente assinalados.

3. A este propósito vale no entanto a pena avançar, recorrendo aos dados do EUROSTAT, que se considerarmos o total da população com o ensino superior, dos 25 aos 64 anos, ao longo da última década, verificamos que, do ano de 2000 para 2009, as taxas de desemprego subiram de 2,5\% para $5,6 \%$. Num contexto de agravamento do desemprego, estas não chegaram, portanto, a duplicar, ao passo que entre os indivíduos com o ensino secundário ou pós-secundário foram bastante além da duplicação (de 3,9\% para 8,2\%), praticamente triplicando junto da população que não foi além do 3.․ ciclo (de 3,4\% para 10,1\%); por outro lado, é apenas junto da população com o ensino superior que se verifica uma quebra do desemprego de 2008 para 2009 (de 5,8\% para 5,6\%), situação inversa à que sucedeu com a população com outros níveis de habilitação.

4. No estudo ODES (2002) a classificação dos diferentes cursos em áreas de estudo seguiu a Classificação Internacional do Tipo de Educação (CITE) que contempla oito grandes grupos: o grupo da "Agricultura" (inclui os cursos de agricultura, silvicultura, pescas e ciências veterinárias); o grupo das "Artes e Humanidades" (cursos de artes e humanidades); o grupo das "Ciências" (cursos de ciências da vida, ciências físicas, matemática e estatística e informática); o grupo das "Ciências Sociais, Comércio e Direito" (cursos de ciências sociais e comportamento, informação e jornalismo, ciências empresariais e direito); o grupo da "Educação" (cursos de formação de professores/formadores e ciências da educação); o grupo da "Engenharia" (cursos de engenharia técnica e afins, indústrias transformadoras, arquitectura e construção); o grupo da "Saúde e Protecção Social" (cursos de saúde e serviços sociais); e o grupo dos "Serviços" (cursos de serviços pessoais e transportes).

5. De acordo com os critérios do INE, a classificação de "desempregado" é atribuída a um "indivíduo com idade mínima de 15 anos que, no período de referência, se encontrava simultaneamente nas situações seguintes: a) não tinha trabalho remunerado nem qualquer outro; b) estava disponível para trabalhar num trabalho remunerado ou não; c) tinha procurado um trabalho, isto é, tinha feito diligências no período especificado (período de referência ou nas três semanas anteriores) para encontrar um emprego remunerado ou não. Consideram-se como diligências: a) contacto com um centro de emprego público ou agências privadas de colocações; $b$ ) contacto com empregadores; c) contactos pessoais ou com associações sindicais; d) colocação, resposta ou análise de anúncios; e) realização de provas ou entrevistas para selecção; f) procura de terrenos, imóveis ou equipamentos; g) solicitação de licenças ou recursos financeiros para a criação de empresa própria". O critério de disponibilidade para aceitar um emprego é fundamentado no seguinte: “a) no desejo de trabalhar; b) na vontade de ter actualmente um emprego remunerado ou uma actividade por conta própria caso consiga obter os recursos necessários; c) na possibilidade de começar a trabalhar no período de referência ou pelo menos nas duas semanas seguintes. Inclui-se o indivíduo que tem um emprego, mas só começa a trabalhar em data posterior à do período de referência até ao prazo limite de três meses, findo o qual passa a ser considerado inactivo" (INE, I.?P., 2006).

6. Como referimos de início, a irregularidade do arco temporal abrangido nos diferentes estudos impede que comparemos os dados que cada um deles veicula. De facto, as diversas investigações 
congregam diferentes coortes de diplomados - no momento da inquirição, os graduados das instituições "algarvias" tinham obtido o seu grau, no máximo, 3 anos antes; na Universidade de Aveiro, de 1 a 5 anos; na Universidade de Évora, de 1 a 5 anos; na Universidade de Lisboa, de 2 a 5 anos; na Universidade do Minho, de 3 a 8 anos; na Universidade do Porto todos tinham finalizado a licenciatura há 3 anos; no Instituto Politécnico de Beja, de 1 a 4 anos; na Escola Superior de Ciências Empresariais, de 1 a 6 anos; e, finalmente, no IST, de 1 a 4 anos.

7. No original, vertically and horizontaly mismatched.

8. No estudo realizado junto dos licenciados da Universidade de Aveiro (Martins, Arroteia e Gonçalves, 2002), foram mobilizadas nove categorias profissionais, a saber: funções dirigentes; profissões intelectuais e científicas; professores do ensino superior universitário; professores do ensino superior politécnico; professores de 2.. e 3.ำ ciclos e ensino secundário; professores de 1.ำ ciclo e educadores de infância; profissões técnicas intermédias; empregados administrativos; e outras.

9. Para os autores, apenas $15,5 \%$ se encontram numa situação de sobrequalificação.

10. A fasquia será de 200?000 escudos no caso do estudo do ODES que decorreu antes da entrada em vigor da moeda única europeia.

11. Ainda em Portugal, Oliveira e Carvalho (2008) avaliaram, em estudo recente, o fenómeno da precarização do emprego nos países da UE mobilizando os dados do EUROSTAT, e assumindo a (in)segurança do vínculo contratual como o indicador central de precariedade. Estes dados permitiram-lhes estimar a evolução do fenómeno da precariedade em vinte e cinco países da UE, e produzir sínteses comparativas extremamente relevantes para o conhecimento destas matérias. Destacamos a de que, em grande parte desses países, apesar da situação de "precarização dos estáveis" (Duarte, 2008), o aumento dos níveis de precariedade não pode ser inferido das "novas condições da economia global", a contracorrente pois de múltiplas análises recentes. Como referem as autoras, contemplando a "geração adulta" (25-49 anos), "Portugal é o país que, depois da Espanha (32,1\%), apresenta maior percentagem $(18,0 \%)$ de trabalho temporário (...), com uma diferença importante: enquanto a Espanha apresenta sinais de retrocesso, Portugal duplicou a percentagem de trabalho temporário na última década, tendo-se agravado nitidamente as condições de inserção profissional da população adulta entre gerações" (Oliveira e Carvalho, 2008: 555).

12. Os inquiridos deste estudo correspondem a uma "amostra representativa dos mestres e doutores que obtiveram os respectivos graus em 1995 ou em 2000 da Universidade de Aveiro, Universidade de Lisboa (Faculdade de Psicologia e de Ciências da Educação), da Universidade Nova de Lisboa (Faculdade de Ciências e Tecnologia) e da Universidade Técnica de Lisboa (Instituto Superior de Economia e Gestão)" (Cabrito, 2008: 107).

13. $O$ estudo dos valores perante o trabalho tem sido proficuamente desenvolvido por um grupo de investigação norte-americano que, através da aplicação de um questionário a várias coortes de diplomados do ensino superior (1976, 1991 e 2006) e de uma análise comparada, monitoriza a evolução dos valores face ao trabalho dos diplomados do ensino superior norte-americano. Tal como nos estudos levados a cabo em Portugal, os jovens licenciados americanos avaliam os factores intrínsecos do trabalho como os mais importantes, embora os valores extrínsecos tenham vindo a ganhar terreno nos últimos anos - para um maior conhecimento do projecto, consultar Twenge, Campbell, Hoffman e Lance, 2010. 


\section{RESUMOS}

Nas últimas décadas, as teses catastrofistas acerca do processo de inserção profissional dos diplomados têm-se instalado de forma relativamente acrítica e indisputada em Portugal. Este artigo pretende sujeitá-las ao escrutínio da empiria. Compilando um vasto conjunto de fontes, demonstrar-se-á que esses juízos são frágeis e longe de ser evidentes. Em sequência, sugerir-se-ão interpretações para o facto inesperado de um número claramente maioritário de diplomados avaliar de forma positiva a sua situação profissional. Com esse objectivo, destacar-se-á a importância que as "dimensões intrínsecas", tendencialmente descuradas pela análise sociológica, adquirem no confronto dos diplomados com o mundo profissional e com o ensino superior.

In the last decades, shattering opinions on the graduates' process of professional insertion have settled in a somewhat uncritical and undisputed manner in Portugal. This article intends to subject them to data scrutiny. Collecting a variety of sources, it will be shown that such thesis have no grounds. Following, interpretations for the unexpected fact that a clear majority of graduates evaluates positively their professional situation come in. Here, the significance that "inner dimensions", tending to be neglected by sociological analysis, acquire in the relation between the graduates and the professional world and higher education will be highlighted.

\section{ÍNDICE}

Keywords: professional insertion, graduates, higher education

Palavras-chave: inserção profissional, diplomados, ensino superior

\section{AUTORES}

\section{MIGUEL CHAVES}

Departamento de Sociologia da FCSH-UNL, CesNova (miguel.chaves@fcsh.unl.pt)

\section{CÉSAR MORAIS}

Departamento de Sociologia da FCSH-UNL, CesNova (cesar.morais@mail.telepac.pt)

\section{JOÃO SEDAS NUNES}

Departamento de Sociologia da FCSH-UNL, CesNova (joaosedasnunes@fcsh.unl.pt) 